\title{
RECONSIDERANDO A NOVA SOCIOLOGIA DA INFÂNCIA
}

\author{
ALAN PROUT \\ Diretor do Instituto da Universidade de Warwick - Conventry, Reino Unido \\ a.prout@warwick.ac.uk \\ Tradução: Fátima Murad
}

\begin{abstract}
RESUMO
Apesar do forte desenvolvimento e da alta produtividade nos últimos anos, a Sociologia da Infância parece estar sem rumo atualmente. Este artigo explora o problema, indicando possíveis causas e apontando algumas soluções. Argumenta-se que a construção de uma Sociologia da Infância implicou uma dupla tarefa: criar um espaço para a infância no discurso sociológico e enfrentar a crescente complexidade e ambiguidade da infância como um fenômeno contemporâneo e instável. Sustenta-se que, embora se tenha criado um espaço para a infância, isto se deu, em grande medida, nos termos de sociologia moderna, que se mostrava cada vez mais incapaz de lidar adequadamente com o mundo instável da modernidade tardia. Um aspecto importante desse problema revela-se pela reprodução, na Sociologia da Infância, das oposições dicotomizadas que caracterizaram a sociologia moderna. Três dessas oposições (ação e estrutura, natureza e cultura, ser e devir) são exploradas. Sugere-se que para libertar a Sociologia da Infância do controle desse pensamento moderno é preciso desenvolver uma estratégia para incluir o terceiro excluído. Entre outras coisas, isso pode exigir maior atenção à interdisciplinaridade, ao hibridismo do mundo social, às suas redes e mediações, à mobilidade e à relação entre gerações.

SOCIOLOGIA - INFÂNCIA - ANTROPOLOGIA - CRIANÇAS
\end{abstract}

\begin{abstract}
RECONSIDERING THE NEW SOCIOLOGY OF CHILDHOOD. Despite its energetic development and high productivity during the last period, the sociology of childhood seems currently to be experiencing a loss of direction. This paper explores this problem, suggesting what its causes may be and pointing to some possible remedies. It is argued that the construction of a sociology of childhood entailed a double task. First, space had to be created for childhood

Esta é uma versão da comunicação originalmente apresentada no $8^{\circ}$ Encontro anual da secção de "Sociologia da Infância" da Associação Alemã de Sociologia, no Max Plank Institut fur Bildunsforschung, Berlim, em maio de 2002. Muitos dos argumentos expostos aqui foram expandidos posteriormente em The future of childhood (Prout, 2005). $O$ texto original sofreu pequenos ajustes para corrigir anacronismos devido à distância entre o momento em que foi escrito e a tradução (cerca de oito anos).
\end{abstract}


within sociological discourse. Second, the increasing complexity and ambiguity of childhood as a contemporary, destabilised phenomenon had to be confronted. It is argued that, whilst a space for childhood has been created, this was accomplished largely in terms of modernist sociology, a discourse that was increasingly unable to deal adequately with the destabilised world of late modernity. An important aspect of this problem is apparent in the reproduction within the sociology of childhood of the dichotomised oppositions that characterise modernist sociology. Three of these oppositions (agency and structure, nature and culture, being and becoming) are explored. It is suggested that moving the sociology of childhood beyond the grip of such modernist thinking entails developing a strategy for 'including the excluded middle'. Inter alia this may necessitate greater attention to interdisciplinarity, the hybridity of the social world, its networks and mediations, mobility and the relationality of generation.

SOCIOLOGY - CHILDHOOD - ANTROPOLOGY - CHILDREN

Há dez anos, em uma conferência em Londres, Barrie Thorne acenou para a necessidade de reflexão e de renovação na Sociologia da Infância, observando que o "novo" paradigma da infância estava ficando velho demais para a criança'. Pouco tempo depois, sociólogos alemães consagraram seu encontro de 2002, em Berlim, para discutir meios de revigorar o campo. Ao mesmo tempo, ouviam-se vozes críticas, tanto internas (por exemplo, Lee, 1999; Alanen, 200 la), como externas (por exemplo, Buckingham, 2000). Assim, parece que depois de mais de duas décadas de um esforço extraordinariamente criativo, que ampliou as perspectivas teóricas, metodológicas e empíricas, a nova Sociologia da Infância está cada vez mais aberta a algumas ideias arrojadas.

Em meu livro O futuro da infância (Prout, 2005), examinei alguns problemas e novos direcionamentos para esse campo. Eles se refletem no presente artigo, embora seja impossível desenvolvê-los integralmente aqui. A principal ideia que sugiro neste texto é que a construção de um lugar para a infância na Sociologia se deu em termos que reproduzem as dicotomias da Sociologia moderna: por exemplo, estrutura e ação, natureza e cultura, ser e devir. É necessário, penso eu, reconsiderar e redirecionar o foco para o "terceiro excluído" dessas oposições. Concluo que isto ajudará a indicar alguns itens para a agenda da Sociologia da Infância em sua próxima fase.

I. Utilizo o termo "nova Sociologia da Infância" em referência ao conjunto dos trabalhos que conceituam as crianças como atores sociais e a infância como entidade ou instituição socialmente construída. Esses trabalhos começaram nos anos 1970, difundiram-se e foram codificados nos 1990. Exemplos são os textos de James, Jenks e Prout (1998), Qvortrup et. al. (1994) e Corsaro (1997). 


\section{CONDIÇÕES DE POSSIBILIDADE DA SOCIOLOGIA DA INFÂNCIA}

Em sua forma contemporânea, ela surgiu nos anos 1980-1990. Três principais recursos teóricos foram empregados em sua construção. Primeiro, apoiou-se na Sociologia interacionista desenvolvida principalmente nos Estados Unidos nos anos 1960. Esta problematizou o conceito de socialização, que torna as crianças muito passivas. Segundo, nos anos 1990, sobretudo na Europa, houve um ressurgimento (um tanto quanto surpreendente) da sociologia estrutural, que vê a infância como um dado permanente da estrutura social. Finalmente, nos anos 1980, na Europa e nos Estados Unidos, o construtivismo social problematizou e desestabilizou todo e qualquer conceito consagrado sobre a infância, lançando-Ihe um olhar relativista. Este enfatizou a especificidade histórica e temporal da infância e dirigiu o foco à sua construção através do discurso.

Esse trabalho foi realizado em um cenário de grandes mudanças sociais.

contexto era o complexo de fenômenos que a teoria sociológica designa hoje por termos como pós-fordismo, modernidade tardia, sociedade em rede da pós-modernidade e sociedade de risco. Não obstante suas diferenças (nas quais não nos deteremos, pois extrapolam os propósitos deste artigo), esses termos referem-se a fenômenos como flexibilização da produção, deslocalização e "esvaziamento" das instituições, fragmentação das fontes de identidade, enfraquecimento do Estado-Nação e de sua ação reguladora, desilusão com o conhecimento racional e a especialização, um sentimento generalizado de incerteza, risco e insegurança, novas práticas de monitoração e reflexividade, a distribuição de normas de democracia, prestação de contas e participação, expansão das redes de conhecimento pondo em circulação ideias novas e mais diversas em um ritmo cada vez mais acelerado, formas plurais de vida familiar, padrões de consumo diversificados e mudanças na participação no mercado de trabalho, no emprego e na economia global.

A infância estava profundamente envolvida nesses fenômenos. Por exemplo, desde meado dos anos 1970, há sinais de uma crise cultural (ou representacional) da infância. Um indicador disso são os textos semiacadêmicos e populares dessa época que anunciavam o "desaparecimento da infância". Postman é bem conhecido, mas há inúmeros outros. Não seria muito difícil desmentir esses críticos. Mas o fato é que eles ajudaram a ver que as velhas 
ideias sobre a infância já não eram adequadas, que estava ocorrendo então, como ocorre ainda hoje, uma modificação no caráter da infância. Inclusive, em alguns aspectos, esses críticos estão corretos ao assinalar o enfraquecimento das fronteiras entre a infância e a idade adulta.

Podemos destacar também a mudança das condições da infância. A ideia de uma infância padrão foi sempre questionável, mas nos anos 1970 e 1980 ficou claro que a experiência da infância estava se fragmentando. A proporção de crianças vivendo em situações familiares "não padrão" já era tão elevada que estas não podiam mais ser vistas como desvios da norma. Além disso, as novas formas de família se diversificaram bastante, e ficou difícil categorizá-las em um esquema rígido com apenas duas ou três variantes. Acrescente-se que, embora isso tenha ocorrido em um contexto de padrões de vida em constante elevação nos países industrializados, há evidência de uma crescente diferenciação entre as crianças que tiraram mais proveito do crescimento da riqueza e as que se beneficiaram menos. Um estudo baseado em dados da Organização para a Cooperação e Desenvolvimento Econômico - OCDE - procurou verificar se a distribuição de renda entre crianças está se tornando mais desigual. Parece que sim. Dos 17 países estudados, 12 mostraram uma desigualdade crescente da renda entre as crianças (Oxley et al., 200 I, p.378).

\section{SOCIOLOGIA MODERNA}

Foi a complexa e caótica desorganização da vida social, refletida na infância contemporânea, mas não confinada a ela, que erodiu a Sociologia moderna e a tornou inadequada para a modernidade tardia. Segundo Bauman, o projeto básico de modernidade era a busca da ordem, da pureza e a determinação de excluir a ambivalência: "O horror à mistura reflete a obsessão pela separação [...] A referência central tanto do intelecto moderno quanto da prática moderna é a oposição - mais precisamente, a dicotomia" (Bauman, 1991, p. |4).

A Sociologia moderna refletiu essa tendência geral. Ela é marcada pela proliferação de tais dicotomias através das quais o mundo social foi dividido em tópicos distintos: estrutura versus ação; local versus global; identidade versus diferença; continuidade versus mudança, e assim por diante. Mas, em face de sociedades que se tornaram marcadamente desordenadas e repletas de fenômenos mistos, híbridos, complexos, impuros, ambivalentes, em constante mutação, 
fluidos e em rede, a teoria social foi obrigada a encontrar termos de análise. Quaisquer que tenham sido os termos inventados, todos tentaram passar a ideia de que a nítida separação das coisas que a modernidade buscou com tanto afinco já não era adequada para a tarefa de compreender a vida social contemporânea.

Foi então, em meio a essa mudança no caráter da vida social e em meio a essa crise da teoria social, que teve início a Sociologia da Infância contemporânea. Começou ligada a uma tradição sociológica e a um aparato teórico que já viviam, eles próprios, um momento de dúvida sobre si mesmos, de instabilidade e de reproblematização. Nos anos 1980 e 1990, a sociologia tentava manter-se em sintonia com um conjunto complexo de mudanças sociais esboçadas anteriormente e que abalaram os pressupostos modernos que the haviam servido de base durante quase todo o século anterior. $\bigcirc$ problema aqui reside em que a teoria social moderna nunca havia dado muito espaço à infância. A Sociologia da Infância surgia então com uma dupla tarefa: criar um espaço para a infância no discurso sociológico e encarar a complexidade e ambiguidade da infância como um fenômeno contemporâneo e instável.

Há muitas exceções a isso, e eu exagero um pouco o quadro para ressaltá-lo, mas minha opinião hoje é que a Sociologia da Infância, no conjunto, está apenas começando a lidar com a segunda parte dessa tarefa. Todo o esforço concentrou-se em abrir um espaço para a infância na Sociologia moderna, em grande medida nos seus termos. Ou seja, isso se deu, em grande medida, dentro de um conjunto de oposições dicotomizadas.

Por exemplo, dois elementos-chave na Sociologia da Infância, a ação das crianças e a ideia de infância como uma estrutura social, vieram diretamente da Sociologia moderna, em uma forma mais ou menos idêntica. Isso levou a alguns estranhos paradoxos. Ao mesmo tempo em que a teoria social se ajustava à modernidade tardia descentrando o sujeito, a Sociologia da Infância valorizava a subjetividade das crianças. Enquanto a Sociologia procurava metáforas para mobilidade, fluidez e complexidade, a Sociologia da Infância ia edificando a infância como uma estrutura. Assim, a Sociologia da Infância chegou ao ápice da modernidade quando a teoria social adequada às transformações em curso na modernidade já estava em processo de constituição. A Sociologia da Infância teve então de correr para acompanhar a teoria social moderna, que, por sua vez, estava ficando confusa com as mudanças sociais que excediam e ultrapassavam seu patamar conceitual. 
Para resumir, o encontro da Sociologia com a infância é marcado pela modernidade tardia. Mas, principalmente, neste sentido irônico: ao mesmo tempo em que os pressupostos sociológicos sobre a modernidade estavam desmoronando, eles se estendiam, tardiamente, à infância.

\section{OS DUALISMOS DA SOCIOLOGIA DA INFÂNCIA}

A Sociologia da Infância estabeleceu-se então, ela própria, dentro, e não além das oposições dicotomizadas da Sociologia moderna. Gostaria aqui de ressaltar três delas: crianças como atores versus infância como estrutura social; infância como constructo social versus infância como natural; e infância como ser versus infância como devir.

\section{Estrutura e ação}

Meu primeiro exemplo de um dualismo problemático codificado dentro da Sociologia da Infância: aquele entre infância como parte da estrutura social e crianças como atores. Em geral, fala-se em Sociologia da Infância, no primeiro caso, e em Sociologia das Crianças, no segundo. Ambas as abordagens, por si mesmas, têm muitas qualidades louváveis.

Assim, a infância como estrutura social tem a ver com a padronização em larga escala da infância de uma determinada sociedade. Chama a atenção, quando se tenta compreendê-la, a distribuição crescente de recursos destinados à infância. Segue por longas cadeias de causa e efeito, de modo que a forma da infância em uma determinada sociedade pode ser moldada por fenômenos distantes dela, espacial e temporalmente. Contudo, do lado problemático, tal abordagem está mais envolvida com o que concebe como entidades estáveis e bem delimitadas, mais comumente o Estado-Nação, e com as variações nos padrões comparativos da infância encontrados dentro dessas entidades e entre elas. Ela não está muito interessada no caráter instável das fronteiras entre sociedades definidas nacionalmente e nas movimentações através dessas fronteiras. Não está preocupada com a relativa diminuição do poder do Estado-Nação para vigiar suas fronteiras e tende a homogeneizar as formas de infância encontradas dentro das fronteiras que imagina seguras. Tende a um certo formalismo matemático, que está mais 
focalizado no padrão do que no modo como ele é produzido e construído. Tende a subestimar o modo como se obteve a escala e a estabilidade. Admite que os padrões de larga escala explicam a ação dos atores individuais e coletivos, em vez de tentar compreender como um padrão de atividade atinge larga escala ou, inclusive, como alcança a estabilidade implícita na metáfora da "estrutura".

Os estudos das crianças como atores são quase a imagem invertida disso. A ideia é que as infâncias, no plural aqui, e não no singular, são construídas mais diversamente e localmente mediante a interação contínua entre atores humanos. A vida social é, ao mesmo tempo, mais contingente e mais frágil, e precisa ser permanentemente trabalhada, mantida e reparada. Embora se reconheçam padrões de larga escala, isso se dá mais gestualmente em referência aos recursos e imposições que supostamente viriam da estrutura "externa". Como isso acontece, é difícil saber em detalhe. Em geral, trata-se apenas superficialmente da ação das crianças como atores; ela é vista como uma característica essencial e quase não mediada dos humanos, que não requer muitas explicações. A verdadeira novidade da abordagem está em considerar que as crianças realmente têm uma determinada ação e que cabe ao pesquisador sair a campo e descobri-la. Nisso, eles tiveram mais êxito.

\section{Natureza e cultura}

Meu segundo exemplo de dicotomias na Sociologia da Infância pode ser compreendido melhor por meio do um exame crítico da infância como uma construção social. Do mesmo modo que a Sociologia interacionista, ela também ressalta a pluralidade de infâncias que coexistem, se sobrepõem e entram em conflito entre si. Sua força está em chamar a atenção para o modo como todos os fenômenos se produzem relacionalmente, o que significa dizer que tanto a idade adulta como a infância são vistas como efeitos produzidos no interior de atos discursivos. Ela vê ação e estrutura do mesmo modo - como efeitos produzidos no interior do discurso. Descentra ambas para saber como elas se produzem mutuamente e sob que condições. Esse gênero de estudos da infância, na medida em que se apoia em textos pós-estruturalistas, desafia diretamente os dualismos da teoria social moderna e, com isso, indica a via para escapar ao domínio deles no âmbito da Sociologia da Infância. 
Entretanto, isso tem um custo enorme: garante ao discurso (narrativa, representação, simbolização etc.) o monopólio como meio pelo qual a vida social, consequentemente a infância, é construída. Relatos sobre a criança socialmente construída privilegiam sempre o discurso. Algumas versões são claramente idealistas sobre a infância, enquanto outras simplesmente silenciam sobre os componentes materiais da vida social. Na melhor das hipóteses, há uma equivocada e difícil omissão sobre a materialidade, seja ela pensada como natureza, corpos, tecnologias, artefatos ou arquiteturas.

É bem conhecido o argumento de Bruno Latour (1993) de que os dualismos da modernidade surgem da separação radical que se estabelece entre cultura e natureza, separação que, ele sugere, foi a condição histórica para a criação das "ciências naturais". Nesse arranjo, a "ciência" encampou a "natureza", pensada como cultura externa, como seu objeto, enquanto "cultura" e "sociedade", pensadas como externas à natureza, foram deixadas para o que viria a ser as "ciências sociais". Como lembrou Urry, "Até muito recentemente, essa divisão acadêmica entre o mundo dos fatos naturais e o dos fatos sociais era incontestável. [...] $\bigcirc$ pressuposto é que existia um abismo entre natureza e sociedade" (2000, p. 10).

Isso diz respeito diretamente à Sociologia da Infância. Se a Sociologia ignorou por tanto tempo a infância, foi porque esta parecia desafiar a divisão entre natureza e cultura.

De fato, Haraway situa a infância entre os fenômenos - os outros são a loucura e o corpo feminino - que burlaram a modernidade, porque se situam dos dois lados da barreira cultura/natureza que ela erigiu. $\bigcirc$ caráter híbrido da infância, em parte natural e em parte social, parece claramente incômodo para a mentalidade moderna, com sua preocupação em dicotomizar os fenômenos. A solução parcial que encontrou, a de ceder a infância à natureza (isto é, às ciências biológicas e médicas ou suas extensões), persistiu até os últimos anos do século XX. Isso foi codificado na Sociologia como a ideia de socialização - devir social. As crianças pertencem à natureza até fazerem parte do social. A fundamentação da Sociologia da Infância na ideia de que a infância é uma construção social revela-se, desse ponto de vista, como um discurso inverso. Abandona o reducionismo biológico e o substitui pelo reducionismo sociológico. Por mais útil que tenha sido para rebater o reducionismo biológico da infância como natural, hoje em dia é um exagero. 


\section{Ser e devir}

Meu terceiro exemplo é a conhecida dicotomia entre crianças como devires e crianças como seres. Em alguns autores da nova Sociologia da Infância, ela foi construída como uma oposição, reafirmada com tanta insistência e de forma tão dogmática que nega a possibilidade de considerar as crianças igualmente como seres e devires. Em outros casos, foi sempre uma oposição problemática. Christensen, por exemplo, em um texto de 1994, mostrou que a distinção entre ser e devir só tinha utilidade se o "ser" das crianças fosse compreendido como vivido no tempo, com um passado lembrado e um futuro antevisto. $\bigcirc$ "ser" que ela concebe não poderia ser incólume ao tempo.

Nick Lee (1999) argumentou, de forma conclusiva, a meu ver, que a Sociologia da Infância deve reconhecer igualmente o ser e o devir. Em primeiro lugar, ele sugere que, embora a oposição fizesse algum sentido do ponto de vista das sociedades modernas, tornou-se insustentável em face das mudanças recentes no emprego e na família. Com elas, o caráter inacabado da vida dos adultos ficou tão visível quanto o das crianças. Nesses termos, tanto os adultos quanto as crianças podem ser vistos como devires, sem deixar de lado a necessidade de respeitar seus estatutos como seres ou pessoas. Em segundo lugar, ao distinguir as crianças como seres "de direito próprio", a nova Sociologia da Infância corre o risco de endossar o mito da pessoa autônoma e independente, como se fosse possível ser humano sem pertencer a uma complexa rede de interdependências. Ele critica então a nova Sociologia da Infância por se basear unilateralmente na ideia de crianças como seres. Tanto crianças como adultos deveriam ser vistos através de uma multiplicidade de devires, nos quais todos são incompletos e dependentes.

\section{ESTRATÉGIAS PARA A INCLUSÃO DO TERCEIRO EXCLUÍDO}

As dicotomias que explorei não são as únicas que perpassam a Sociologia da Infância. Contudo, a questão não é elaborar uma lista exaustiva delas, mas identificar o problema-chave criado por essa divisão de campo. Não se trata tampouco de afirmar que o trabalho baseado nessas oposições não produz novos conhecimentos, e sim de considerar que, como categorias teóricas, elas se tornaram mutuamente exclusivas. É difícil encontrar algum ponto de comu- 
nicação entre elas, visto que cada uma se define fora do domínio das outras, seja suprimindo tudo o que Ihes sirva de mediação, seja distribuindo-o entre si para que se torne propriedade de uma ou de outra. Desviam a atenção das mediações e conexões entre as oposições que erigem. Assim, excluem tudo o que se situe abaixo delas e entre elas, suprimindo sua dependência mútua e ocultando aspectos importantes sobre o modo como se constroem as infâncias contemporâneas.

Diante disso, na última parte do artigo, pretendo tratar de algumas estratégias para superar essa situação e encontrar meios de incluir o terceiro excluído.

Atualmente, existem duas linhas de abordagem do problema, nenhuma delas adequada.

A primeira é a que chamo de "coexistência pacífica" (que é, naturalmente, outra forma de dizer "guerra fria"). Na melhor das hipóteses, isso significou autorizar que diferentes sociologias da infância, localizadas em diferentes polos de uma dicotomia, seguissem caminhos separados, sem se preocupar muito em explorar o território que as conecta. Isso é evidente, por exemplo, no texto de Bill Corsaro, The sociology of childhood (1997).

A segunda é a que chamo de "jogo heurístico". É mais ou menos a estratégia sugerida em Theorising childhood, que escrevi com Alison James e Chris Jenks. Identificamos ali diferentes abordagens da Sociologia da Infância, situando-as em um conjunto de dualismos que, a nosso ver, caracterizam as crenças e os valores da teoria sociológica: ação e estrutura; identidade e diferença; continuidade e mudança; localismo e globalismo. Argumentamos que o modo como esses dualismos foram selecionados, atravessados e desenvolvidos por analistas da infância delineou quatro gêneros principais de Sociologia da Infância, que também identificamos (James, Jenks, Prout, 1998).

Depois de formalizar a desconexão entre esses gêneros, recorremos aos sociólogos da infância para examiná-los, procurando novos pontos de conexão e intersecção entre eles. Isso poderia dar algum resultado - inclusive, é o que muitas pesquisas empíricas fazem diante de realidades complexas. Contudo, ao tomar como principal ponto de referência aquele que focaliza o discurso dualista da Sociologia, corremos o risco de nele entrincheirar a Sociologia da Infância, limitando assim a área em que o campo poderia avançar.

Se essas duas abordagens são inadequadas, sugiro então, como alternativa, desenvolver e explorar novas ideias. Essas ideias deveriam ter como foco 
o terceiro excluído e nos ajudar a incluí-lo. Em outras palavras, não deveriam de antemão inscrever um conjunto de dicotomias no campo, e sim observar a infância como um fenômeno complexo, não imediatamente redutível a um extremo ou outro de uma separação polarizada. Não estou advogando aqui um obsoleto "caminho do meio". A abordagem que tenho em mente é similar à do autor italiano Norberto Bobbio, quando se refere ao "terceiro incluído": "ele tenta encontrar seu próprio espaço entre dois opostos e, embora se insira entre eles, não os elimina [...] eles deixam de ser duas totalidades mutuamente exclusivas, como as duas faces da mesma moeda, que não podem ser vistas ao mesmo tempo" (Bobbio, 1996, p.7).

Bobbio, no entanto, fala de uma síntese superior, feita de oposições. Quanto a isso, não estou tão certo. Estou mais preocupado em situar o plano mais fundo onde essas oposições se erigem... ou desmoronam. Isso está mais próximo do ator-rede de Latour (1993) ou da noção de rizoma encontrada em Deleuze e Guattari (1988).

Nos dois casos, a atenção é direcionada aos materiais e práticas a partir dos quais é gerada e emerge uma infinidade de novos fenômenos, incluindo distinções e dicotomias. Esse é o terceiro excluído que constrói a infância e para o qual sugiro dirigir nosso olhar. Para isso, gostaria de indicar cinco palavras-chave que podem nos servir de guia em uma tal empreitada.

\section{Interdisciplinaridade}

Uma implicação prática imediata de minha argumentação é a necessidade de intensificar a interdisciplinaridade dos estudos da infância. $\bigcirc$ campo é já significativamente interdisciplinar graças às contribuições da Sociologia, da Geografia Humana, da Antropologia, da História etc. No entanto, existem áreas em que o diálogo interdisciplinar é fraco. Uma delas é a Psicologia, que, de algum modo, foi a disciplina contra a qual a nova Sociologia de Infância se constituiu como oposto: crianças como indivíduos versus crianças como seres sociais. Sustentar essa posição significava apegar-se a estereótipos banais do engajamento da Psicologia com a infância. Mas, é evidente que pelo menos alguns psicólogos se preocupam com muitas questões parecidas. Em particular, a Psicologia crítica procurou descobrir novas formas de compreender a relação entre sociedade individual e cultura. Exemplos são os trabalhos de Martin 
Woodhead, no Reino Unido, Michael Cole, nos Estados Unidos, Jaqueline Goodnow, na Austrália, e Hanna Havind, na Noruega.

Seria útil aqui que houvesse mais diálogo, que se explorasse a base comum, assim como as diferenças. A maior dificuldade talvez seja o tempo que levará para se dialogar mais diretamente com as ciências biológicas e médicas que, para o bem ou para o mal, têm um importante papel na compreensão e constituição da infância na sociedade contemporânea.

\section{Hibridismo}

A principal razão para a interdisciplinaridade é o reconhecimento de que a infância é um fenômeno complexo. Essa complexidade resulta do seu caráter híbrido, constituído mediante o que Latour chama de "redes heterogêneas do social". Estas são, segundo ele, "simultaneamente reais, como a natureza, narradas, como o discurso, e coletivas, como a sociedade" (Latour, 1993, p.6).

Apenas quando a vida social é reconhecida como heterogênea, a divisão a priori de entidades (pessoas, adultos, crianças, corpos, mentes, artefatos, animais, plantas, arquiteturas etc.) entre cultura e natureza torna-se pensável. Os fenômenos sociais devem ser compreendidos como entidades complexas nas quais se dá um misto de cultura e natureza como condição de possibilidade. Não existem mais entidades puras, apenas híbridas, que Latour qualifica de "quase-sujeitos" e "quase-objetos". Nem é preciso dizer que isso é muito mais desafiador analiticamente do que partir de uma divisão estável e predeterminada entre o natural e o cultural.

Redes cada vez mais extensas de elementos heterogêneos seguem o curso de vida em combinações que são empiricamente variadas, mas que, em princípio, não requerem tipos diferentes de análise. Assim, não é necessário separar arbitrariamente as crianças dos adultos, como se fossem espécies de ser diferentes. Em vez disso, a tarefa consiste em saber quantas versões distintas de criança ou adulto emergem da complexa interação, rede e orquestração entre diferentes materiais naturais, discursivos, coletivos e híbridos.

Em um livro sobre a infância e o corpo (Prout, 2000), argumentei que essa abordagem nos permite reincluir a materialidade na análise da infância. Ela nos permite ver a infância não apenas integrada, mas também enredada em uma enorme variedade de artefatos materiais. O livro cita como exemplos 
relações entre crianças e tecnologia médica em uma unidade de tratamento pediátrico intensivo, entre crianças e instrumentos musicais em uma análise do filme $O$ Piano, e entre crianças e câmeras de vídeo em depoimentos aos tribunais do Reino Unido.

\section{Redes e mediações}

Isto conduz a uma preocupação comum de encontrar uma linguagem analítica para falar sobre a ordenação da infância. A nova Sociologia da Infância oferece-nos três opções, todas elas problemáticas. A primeira é constituída de metáforas do tipo "infância como estrutura", "sistema" e "ordem" que enfatizam a larga escala, a estabilidade e o determinismo. A segunda, derivada do interacionismo, apresenta noções de infância como uma ordem local negociada. Enfatiza o trabalho de atores, mas tende frequentemente ao voluntarismo. A terceira é apresentada pelo pós-modernismo, que abandona as noções de estabilidade, vendo apenas fluidez e mudança constante.

A teoria do ator-rede oferece uma outra opção. Usando a metáfora da "rede", sugere que a infância poderia ser vista como um conjunto de ordens distintas, às vezes concorrentes e às vezes em conflito. Estas podem ser frágeis, mas podem também estabilizar-se, difundir-se, e, com isso, ser encontradas em larga escala. A rede parece proporcionar uma linguagem da ordenação, que se situa entre as oposições polarizadas oferecidas pela teoria social moderna.

Por exemplo, a teoria do ator-rede tem um meio eficaz de se livrar da dicotomia ação/estrutura. Em primeiro lugar, afirma que os atores podem ser de diferentes tipos: humanos, como no caso das crianças e adultos, mas também não humanos, como artefatos e tecnologias. Todos eles são tratados como híbridos de cultura e natureza, produzidos por redes de conexão e desconexão. Em segundo lugar, afirma que, em decorrência disso, os atores se apresentam em todos os tamanhos, dos pequenos, como a criança individual, aos grandes, como o Estado ou a mídia. É por isso que todos os atores são vistos como redes, embora possam aparecer e agir como pontos. Por detrás de cada ator, seja uma criança, seja o Estado ou a mídia, há uma rede complexa, mais ou menos unida, de pessoas e coisas. Redes que se estabilizaram aparecem como os objetos sólidos que a Sociologia moderna gostava de chamar de "estrutura" ou "sistema". Mas essas redes podem se tornar frágeis, e são sempre parciais 
e perecíveis. Podem surgir novas redes que ou se perdem no caminho, ou se estabilizam e crescem em escala. Em outras palavras, novas formas de infância aparecem quando se criam novos espaços de conexões em rede, por exemplo, entre crianças e tecnologias, como a TV e a internet. Essas novas redes podem se sobrepor e coexistir com outras mais antigas, mas também podem entrar em conflito com elas. Uma questão-chave, portanto, é saber que rede produz uma forma particular de infância ou de criança.

Em O futuro da infância, de 2005, esboço uma posição parecida, apoiando-me não apenas em Latour e na teoria do ator-rede, mas também nas noções de extensão e reunião, emprestadas de Deleuze e Guattari. Lee (1999) desenvolveu uma posição similar, recorrendo às ideias de extensão e reunião para discutir uma série de exemplos, que vão do conflito entre crianças de rua e a polícia no Brasil até o uso de vídeos com testemunhos de crianças em casos de abuso nos tribunais do Reino Unido. Ele esclarece essas ideias mostrando como diferentes combinações de elementos humanos e não humanos podem ser tratadas como diferentes ordenações da infância, parciais e mais ou menos estáveis, que podem se sobrepor e se apoiar mutuamente ou entrar em conflito.

\section{Mobilidade}

A preocupação em focalizar o terceiro incluído significa também priorizar a mobilidade e os fluxos entre fronteiras. Segundo Urry (2000), o declínio da noção de sociedade como entidade distinta e delimitada, vigente no século XX, requer nova ênfase sociológica na mobilidade. "Sociedades" são cada vez menos capazes de defender suas fronteiras sempre mais permeáveis, e tendem a adotar um nível mais baixo de defesa, na tentativa de regular e moderar novos e intensos fluxos de pessoas, informações e produtos que as atravessam.

Esses processos têm implicações para a infância. Um aspecto da questão é bem ilustrado na pesquisa sobre "infâncias transnacionais", realizada por Thorne e colaboradores, na Califórnia, que mostra a impossibilidade de compreender a variedade e a complexidade da infância sem levar em conta o movimento (Orellana et al., 200 I). A pesquisa apresenta crianças movimentando-se de um lado a outro das fronteiras nacionais, compondo e recompondo, voltando e saindo de casa. São membros de famílias nos Estados Unidos e em outro país (por exemplo, Taiwan ou Filipinas). Essas crianças vêm geralmente de famílias 
pobres e usam ligações com parentes ou conhecidos nos Estados Unidos como rota para a mobilidade social.

Frønes ( 1997), por sua vez, mostrou a emergência de formas de infância altamente confinadas entre as classes médias em ascensão profissional. Estas são encontradas igualmente em Nova lorque, em Nova Déli ou Copenhague. Essas crianças são as beneficiárias da economia em rede de Castell.

Esses fluxos delineiam a conexão entre o global e o local, entre o grande e o pequeno, entre o grandioso e o mundano. Assim, a mobilidade é uma questão central, qualquer que seja a escala de nosso estudo. Um trabalho de Christensen, James e Jenks (2002) mostra que a casa é constituída pelas crianças e para as crianças. Entrevistas com crianças sobre o significado de "tempo em família" sugerem que a "casa", tradicionalmente compreendida mediante o conceito de estabilidade, é também, para as crianças, um lugar cujo significado é dado pelas "idas e vindas" de diferentes membros da família, à medida que se movem dentro e fora do espaço que chamamos de casa.

Mas, assim como as pessoas, as mobilidades transnacionais envolvem fluxos de produtos, informações, valores e imagens com os quais algumas crianças são capazes de interagir rotineiramente. Isso chamou a atenção de estudiosos da mídia, como David Buckingham (2000), que criticaram com razão os novos Estudos Sociais da Infância por ignorarem esse aspecto da vida das crianças. Vista globalmente, a cultura da infância e da juventude está se tornando cada vez mais homogênea.

De fato, esse fluxo de produtos, informações, valores e imagens tem profundas implicações para a socialização e, em certo sentido, criou as bases para a nova Sociologia da Infância. Processos de socialização cada vez mais complexos ocorrem quando crianças pequenas passam a viver grande parte de sua vida cotidiana longe da família - na escola, em centros de recreação ou com baby-sitters. Isso deu origem à ideia de "dupla socialização". O educador alemão Giesecke (1985) alertou, no entanto, que hoje temos de reconhecer também que as crianças, assim como os adultos, vivem em uma sociedade pluralista. São confrontadas com uma série de valores e perspectivas concorrentes, complementares e divergentes dos pais, da escola, da mídia, da sociedade de consumo e de seu círculo de relações. Ainda segundo Giesecke, pais, professores e outros responsáveis pelo cuidado das crianças têm menos poder para controlar e direcionar esses diversos fatores em sua totalidade. Por isso, é importante compreender 
as crianças nas suas tentativas, individuais e coletivas, de dar coerência e sentido ao mundo em que vivem (Christensen, Prout, 2004).

Os lugares da infância podem ser vistos, neste caso, pelos fluxos que passam por eles.

Escolas, por exemplo, são relacionadas a outras escolas, à casa, aos parques, aos centros de recreação, às empresas, às autoridades locais, aos sindicatos, ministérios, tribunais e assim por diante. Pessoas cruzam essas fronteiras levando consigo ideias, experiências, ideais, valores e visões (tudo o que forma os discursos) diferentes e conflitantes, assim como recursos materiais diversos. Coisas também cruzam as fronteiras, e não são menos importantes. Isso inclui textos, orientações curriculares, materiais didáticos, modelos de política de financiamento etc.; e ainda máquinas (como computadores) que funcionam deste e não daquele modo, ou que favorecem aquela e não esta possibilidade de aprender, e assim por diante. Os atores híbridos, pessoas e coisas, que se movimentam em e entre diferentes locais, todos têm um papel na construção daquilo que emerge como "infância". É preciso retraçar esses movimentos para compreendê-los melhor.

\section{A análise relacional: geração e trajetória de vida}

Por último, gostaria de examinar o conceito de "relação entre gerações", tal como formulado por Leena Alanen. Essa abordagem procura estabelecer a ideia de um "sistema geracional" ou "ordem" ao lado das noções de ordem de classe ou ordem de gênero a que os sociólogos costumam se referir quando falam em estrutura social. Nessa definição, a geração é vista como um sistema de relações no qual se produzem as posições de "criança" e de "adulto". Para Alanen, a geração pode ser pensada como: "um sistema socialmente construído de relações entre posições sociais, no qual crianças e adultos detêm posições sociais específicas, definidas em relação às outras e constituindo, por sua vez, estruturas específicas (no caso, geracionais)" (200 I, p. I2).

Neste aspecto, a ideia estrutural de geração está menos explicitamente preocupada com a mudança ao longo do tempo do que a de Mannheim. Está mais centrada no padrão de relações entre adultos e crianças, na medida em que estas constituem um elemento mais ou menos duradouro e estável dos sistemas sociais. 
As questões investigativas que a abordagem prioriza estão voltadas, portanto, a "detectar as relações invisíveis, diretas e indiretas, através das quais as crianças se incorporam firmemente em conjuntos estruturados de relações sociais mais amplas do que suas relações locais muito imediatas e potencialmente extensíveis ao sistema social global" (Alanen, 200 I, p. I 42). Acredita-se que isso pode ser obtido por meio de estudos que examinem a vida cotidiana de crianças, entre outras coisas, em termos de práticas "geracionais" e o modo como se tornam disponíveis os recursos (materiais, sociais e culturais) dos quais dependem essas práticas particulares.

Essa posição, em muitos aspectos, é compatível com a proposta que esboço neste artigo. Está preocupada com o "terceiro excluído", visto que deixa de ver a infância como uma categoria essencializada para vê-la como algo que se produz dentro de um conjunto de relações. É paralela à mudança na Sociologia feminista, que desviou o foco das "mulheres" para se preocupar com "gênero". Nesse sentido, dirige o olhar às relações no interior das quais se produzem a infância e a idade adulta. Está interessada também, em princípio, nos recursos tanto discursivos como materiais e nas práticas envolvidas na construção da infância. Assim, no mínimo, está aberta ao caráter híbrido da infância.

Contudo, há muitos problemas na abordagem de Alanen que precisam ser discutidos.

Primeiro, em sua formulação corrente, a ideia de ordem geracional restringe o alcance de relações que se supõe que a criança mantenha. De fato, há apenas duas posições de sujeito: adulto e criança. Isso parece desnecessariamente abstrato em vista do alcance da infância e da idade adulta que é capaz de registrar. Além disso, por se tratar de um sistema binário que gira em torno de adulto e criança, está centrado em relações intergeracionais, e é difícil ver como as relações intrageracionais podem ser adequadamente reconhecidas. As relações intrageracionais são bastante diversas e apenas captadas de maneira inadequada pelo termo relações entre pares. Não obstante, há bons argumentos e muitas evidências de que essas relações intrageracionais, de pares ou outras, desempenham um papel importante na vida das crianças.

Segundo, em suas formulações correntes, o conceito de geração utiliza uma linguagem de sistema ou estrutura, em vez de rede, rizoma ou reunião. Assim, tende a supervalorizar a estabilidade e a solidez das relações intergera- 
cionais. Como consequência, acaba caindo de novo na ideia de uma estrutura geracional única, cujas variações empíricas são meros exemplos. Daí resulta que há sempre apenas duas gerações na existência - uma alegação estranha e nada sutil de um ponto de vista mannheimiano. Isso aumenta o risco de transformar a geração de processos em produto acabado, uma abstração sociológica utilizada preferentemente para explicar e não como algo que precisa de explicação. Para mim, o importante é manter o processo geracional aberto e sem um propósito determinado, e a pluralidade e o alcance dos "ordenamentos geracionais" abertos à investigação.

Um estudo recente que emprega esses referenciais, mas que também mostrou suas limitações, é o realizado por meus colegas em Stirling, Greg Mannion e John l'Anson. Eles estudaram uma organização artística dedicada especialmente a atender crianças e jovens e conhecida por promover a sua participação. Em particular, eles acompanharam o processo pelo qual as crianças participaram no redesenho do espaço físico do centro de artes. Para mim, esse estudo sugere que é possível entender as relações geracionais como um produto inacabado, contingente e emergente das interações entre elementos heterogêneos - materiais, culturais, espaciais, discursivos etc.

São essas interações, mais do que o trabalho misterioso de uma estrutura geracional subjacente, mas invisível e necessária, que determinam e produzem relações geracionais. $\bigcirc$ estudo mostra como os adultos e crianças, ao descobrirem novas formas de trabalhar juntos, não apenas reconfiguraram o espaço e a organização material do lugar, mas também, como parte disso, modificaram as identificações adulto-criança, as relações e construções associadas da idade adulta e da infância. Mostram que estas estão longe de ser estáveis e fixas. Os autores, apoiados na noção de Deleuze de um devir inacabado e não teleológico, comentam: "Ao invés de apenas enfatizar que crianças também são seres, mostramos como é producente considerar tanto o adulto como a criança como devires parciais" (Mannion, l'Anson, 2003, p.2I).

A este respeito, parece-me razoável considerar o interesse para o estudo da infância de um outro conceito relacional - o da trajetória de vida. A análise da trajetória de vida é um tema amplo, que inclui tempo histórico (gerações e coortes), tempo individual (história de vida e biografia) e tempo institucional (carreiras, sequências e transições). Nas três abordagens, a trajetória de vida é entendida como uma sequência de estágios ou configurações de status e 
transições na vida que são cultural e institucionalmente demarcadas, do nascimento até a morte.

Sob algumas condições, isso me parece constituir também uma referência útil para avançar nos estudos das relações das crianças. As razões que me levam a pensar assim decorrem da posição que defendi antes. Primeiro, fundamenta-se na crítica interna aos estudos da infância por se centrarem exclusivamente no ser das crianças, o que sempre foi problemático (Christensen, 1994). Segundo, uma abordagem da trajetória de vida conduz à multiplicidade e complexidade de infâncias. Para começar, não reduz o fenômeno a uma relação lógica ou interna entre dois termos apenas - adulto e criança. Reconhece justamente o que Alanen deseja excluir - ou seja, a importância das contingências externas na moldagem de infâncias particulares. Enfatiza que as trajetórias de vida estão abertas ao efeito de um amplo leque de fatores humanos e não humanos na construção de múltiplas versões da infância e da idade adulta à medida que se modificam ao longo do tempo. Como vimos, Bruno Latour usa o termo "redes heterogêneas do social", simultaneamente reais, como a natureza, narradas, como o discurso, e coletivas, como a sociedade, para indicar essas formas e esse conteúdo complexos no interior dos quais se constitui a vida humana (1993, p.6).

Essas redes mutáveis de elementos heterogêneos acompanham a trajetória de vida em combinações empiricamente variadas, mas, em princípio, não requerem tipos de análise diferentes. Não é necessário, por exemplo, separar arbitrariamente as crianças dos adultos, como se fossem espécies diferentes de ser. Ao contrário, a tarefa é verificar como diferentes versões de criança ou adulto emergem da interação complexa, das redes e da orquestração de diferentes materiais naturais, discursivos, coletivos e híbridos.

Um dos problemas da abordagem convencional da trajetória de vida é que, muitas vezes, ela classifica a infância como uma simples etapa ou fase desta. Mas esse não é um elemento necessário da abordagem. Assim como a idade adulta, a infância pode ser vista, em uma perspectiva de trajetória de vida, como um conjunto constituído de múltiplas fases decorrentes da experiência. Um exemplo vem, mais uma vez, de Christensen (2003). Em seu trabalho sobre crianças e alimentação, ela trata a infância como um conjunto de fases socialmente construídas. $\bigcirc$ significado e as práticas alimentares mudam de acordo com a relevância da trajetória de vida e com as metas das crianças. 
Assim, por exemplo, embora o tema da competência permeie a trajetória de vida das crianças, seu significado no que se refere ao alimento varia conforme sua posição em relação às metas e práticas mutáveis, mas socialmente estabelecidas, das crianças.

Tal visão da trajetória de vida não apenas condiz com a importância que as próprias crianças atribuem ao "crescer", como tem o mérito de atribuir um papel relevante às relações entre as crianças. Os trabalhos de pesquisadores tão diferentes como Barrie Thorne, Bill Corsaro, Judith Rich Harris e Ivar Frønes mostraram como é importante reconhecer que o "crescer" não se realiza individualmente, mas coletivamente - ou seja, no contexto de relações de grupo. Corsaro ( 1 997) mostra que as crianças descobrem juntas como realizar transições institucionais decisivas, como da pré-escola para a etapa seguinte. Frønes (1997), em particular, argumenta que as relações entre pares, igualitárias, mas complexas do ponto de vista da comunicação, desenvolvem as competências de expressão, de intimidade e de formação comunitária exigidas pela modernidade, entendidas como mais do que simples cálculo racional. Contudo, é preciso também ter o cuidado de não limitar as relações das crianças entre si à categoria de pares. $\bigcirc$ termo é um pouco impreciso, e seria inaceitável na análise das relações entre adultos - exatamente porque tende a sobrepor tipos de relações muito distintas, como as de trabalho, de vizinhança e de amizade. Tende a simplificar e a dar uma coerência que não existe às relações entre crianças. Deixa escapar as relações entre crianças pequenas e crianças mais velhas.

Uma perspectiva de trajetória de vida, entendida em termos de heterogeneidade, pode, no entanto, conter toda essa variação, na medida em que se move entre tempo histórico, tempo individual e tempo institucional. Mostra como as estruturas institucionais podem tanto construir como inviabilizar relações entre crianças. Por exemplo, é possível criar relações de pares juntando crianças da mesma idade na mesma classe, mas a amizade entre uma criança mais velha e uma mais nova fica inviável quando uma vai para o ensino médio e a outra não.

\section{CONCLUSÃO}

A linguagem do hibridismo, da rede, da mobilidade e da reunião, a meu ver, é um bom caminho a seguir se quisermos reconectar o terceiro excluído da 
Sociologia da Infância. É menos propensa a reafirmar as oposições dicotomizadas da teoria social moderna. E mais propensa a sustentar a desestabilização e a pluralização tanto da infância quanto da idade adulta que marcam nossa época. E mais ainda, a compreender as mobilidades que as produziram. Em suma, é parte da "passagem da modernidade" que, na minha opinião, a Sociologia da Infância precisa fazer agora.

\section{REFERÊNCIAS BIBLIOGRÁFICAS}

ALANEN, L. Childhood as a generational condition: children's daily life in a central Finland town. In ALANEN, L.; MAYALL, B. (Ed.). Conceptualizing child-adult relations. London: Falmer, 200 I. . Explorations in generational analysis. In: ALANEN, L.; MAYALL, B. (Ed.). Conceptualizing child-adult relations. London: Falmer, $200 \mathrm{la}$.

BAUMAN, Z. Modernity and ambivalence. Cambridge: Polity, 1991.

BOBBIO, N. Left and right: the significance of a political distinction. Cambridge: Polity, 1996. BUCKINGHAM, D. After the death of childhood: growing up in the age of the electronic media. Cambridge: Polity, 2000.

CHRISTENSEN, P. Children as the cultural other. KEA: Zeischrift fur Kulturwissenschaften, Tema: Kinderwelten, Marburg, n.6, p. I-16, 1994.

. Børn, mad og daglige rutiner. Barn. Tema: barn og mat. Smakebiter fra aktuell forskning, n. 2/3, p. I19-135, 2003. Norsk senter for barneforskning.

CHRISTENSEN, P.; JAMES, A.; JENKS, C. Home and movement: children constructing family time. In: HOLLOWAY, S.; VALENTINE, G. (Ed.). Children's geographies: living, playing and transforming everyday worlds. London: Routledge, 2002. p. I 20- 134.

CHRISTENSEN, P.; PROUT, A. Anthropological and sociological perspectives on the study of children. In: GREENE, S.; HOGAN, D. Researching children's experience: approachs and methods. London: Sage, 2004.

CORSARO, W.A. The Sociology of childhood. Thousand Oaks: Pine Forge, 1997.

DELEUZE, G.; GUATTARI, F. A Thousand plateaus: capitalism and schizophrenia, 2. London: Athlone, 1988.

FRØNES, I. Children of the post-industrial family. Oslo: Department of Sociology and Human Geography, University of Oslo, 1997. Mimeo. 
GIESECKE, H. Das Ende der Erziehung. Stuttgart: Klett-Cotta-Verlag, 1985.

JAMES, A.; JENKS, C.; PROUT, A. Theorising childhood. Cambridge: Polity, 1998.

LATOUR, B. We have never been modern. Hemel Hempstead: HarvesterMheatsheaf, 1993.

LEE, N. The Challenge of childhood: the distribution of childhood's ambiguity in adult institutions. Childhood, Thousand Oaks, v.6, n.4, p.455-74, 1999.

MANNION, G.; I'ANSON, J. New assemblages within the arts fold: exploring young people's subjectification through self-directed photography, photo-journey and photoelicitation. In: CONFERENCE OF THE ENVIRONMENTAL PSYCHOLOGY, 3: CROSSING BOUNDARIES: THE VALUE OF INTERDISCIPLINARY RESEARCH. Proceedings... UK Network, June 2003.

ORELLANA, M. F. et al. Transnational childhoods: the participation of children in the process of family migration. Social Problems Journal, California, v.48, n.4, p.573-592, Nov. 200 I.

OXLEY, $\mathrm{H}$. et al. Income inequalities and poverty among children and households in selected OECD countries. In: VLEMINEKX, K.; SMEEDING, T.M. (Ed.). Child well-being, child poverty and child policy in modern nations. Bristol: Policy, $200 \mathrm{I}$.

PROUT, A Childhood bodies, construction, agency and hybridity. In: PROUT, A. (Ed.). The body, childhood and cociety. London: Macmillan, 2000.

. The Future of childhood: towards the interdisciplinary study of children. London: RoutledgeFalmer, 2005.

QVORTRUP, J. et al. (Ed.). Childhood matters: social theory, practice and politics. Aldershot: Avebury, 1994.

URRY, J. Sociology beyond societies: mobilities for the twenty-first century. London: Routledge, 2000.

Recebido em: setembro 2010

Aprovado para publicação em: setembro 2010 